\title{
A case of type 1 Gaucher disease
}

\author{
G N Lucas ${ }^{1}$, S. Sriranganathan ${ }^{2}$ \\ Sri Lanka Journal of Child Health, 2003; 32: 54-5
}

(Key words: type I Gaucher disease)

\section{Introduction}

Gaucher disease is the commonest glycolipid storage disease, characterized by abnormal accumulation of glucocerebroside in cells of the reticuloendothelial system. It is caused by inherited deficiency of lysosomal enzyme glucocerebrosidase. The birth incidence of this autosomal recessive disease is high $(0.2 \%)$ among the Ashekenazi Jewish population ${ }^{1}$. There are 3 major types based mainly on presence or absence and severity of neurological manifestations. Type 1, the commonest, is characterized by absence of neurological involvement. Even though type 1 has been termed "Adult type", it usually presents in childhood $^{2}$.

\section{Case report}

A seven year old girl was admitted to Lady Ridgeway Hospital (LRH) in June 1998 with a history of progressive enlargement of abdomen and growth retardation since the age of 1 year. She was born normally and the mother noted that her growth was not in keeping with other children of similar age. She has taken the child to several institutions where different investigations were done with no definite diagnosis. By that time, mother noted that the child's abdomen was also enlarging progressively. When she was brought to LRH, in addition to these cardinal symptoms, there was a history of repeated infections, lethargy and easy bruisability. She was the product of a non-consanguineous marriage and there was no family history of similar illness.

She was wasted; both height $(90 \mathrm{~cm})$ and weight $(11.5 \mathrm{~kg})$ were less than $3^{\text {rd }}$ centile. She was pale and examination of abdomen revealed gross splenomegaly (15-17 cm below left costal margin) and moderate hepatomegaly. There were no neurological signs. Her development was age appropriate and she was noted to have a good drawing skill.

${ }^{1}$ Consultant Paediatrician, ${ }^{2}$ Senior Registrar, Lady Ridgeway Hospital, Colombo.

(Received on 13 March 2003)
Initial investigations showed normal blood counts except for mild thrombocytopenia; x-rays, acid phosphatase and echocardiogram were normal. An ultrasound scan of abdomen confirmed the clinical findings. Bone marrow biopsy showed numerous Gaucher cells. Definitive enzymatic diagnosis could not be performed. A diagnosis of Gaucher disease was made based on clinical presentation and presence of Gaucher cells in bone marrow. Since there were no neurological abnormalities until presentation, diagnosis was narrowed to Gaucher disease type 1 .

She was started on "Cerezyme" in April 1999, initially on a low dose for first 3 months and later on the standard regime. She was monitored by quality of life, episodes of infection, growth parameters, blood counts, skeletal survey and visceral volume. After about 4 months of treatment, her weight was gradually picking up, blood counts improved (platelets rose from $150 \times 10^{9} / \mathrm{L}$ to $205 \times 10^{9} / \mathrm{L}$ ) and there were no episodes of infections. The treatment is being continued.

\section{Discussion}

In a series of 34 children with adult type Gaucher disease, majority presented before the age of 10 years and growth retardation with hepatosplenomegaly were prominent features. $90 \%$ of children in this series had radiological features of skeletal involvement ${ }^{2}$.

Common laboratory findings in type 1 Gaucher disease are anaemia, thrombocytopenia and elevated levels of serum acid phosphatase. Diagnosis of Gaucher disease should be considered in any patient with unexplained splenomegaly and is strongly supported by elevated levels of serum acid phosphatase and presence of typical Gaucher cells in bone marrow $^{3}$. It is confirmed with results of an assay of glucocerebrosidase in white blood cells, fibroblast culture $^{4}$ or urine ${ }^{5}$.

The child described here had the classical presentation of growth retardation and progressive abdo- 
minal distension; she did not show any neurological deficits and did not have skeletal abnormalities. Together with presence of Gaucher cells in bone marrow, the diagnosis of Type 1 Gaucher disease was made.

Treatment of type 1 Gaucher disease was entirely symptomatic until recently. Splenectomy is effective in correcting thrombocytopenia and anaemia and eliminates the distress caused by the massively enlarged spleen ${ }^{2}$. Hydration, analgesics, narcotics for pain in bone crisis and orthopaedic interventions for fractures help to maintain the quality of life. Bone marrow transplantation is an effective form of therapy but the risk of mortality and morbidity makes this mode of treatment less desirable ${ }^{6}$.

For type 1 disease, there is good evidence that enzyme replacement therapy (ERT) with mannose terminated placental, or recombinant glucocerebrosidase is beneficial in reducing hepatosplenomegaly, improving haematological parameters, and to a lesser extent alleviating bone disease $^{6}$. Over 1500 patients are now on ERT. Marked organomegaly, severe/moderate cytopenias and extensive skeletal involvement are common indications to initiate ERT. Major disadvantages are cost of therapy, determination of effective initial and maintenance doses and difficulties in administration. Even in USA, cost of therapy for each patient ranges from $\$ 100,000$ to $\$ 400,000$ annually. For developing countries like Sri Lanka, cost of treating a single patient with ERT from annual drug budget is impossible.

\section{References}

1. Beutler E, Nguyen N J, Henneberger H W, et al. Gaucher disease: Gene frequencies in the Ashekenazi Jewish population. Am J Hum Genet 1993; 52: 85-8.

2. Zevin S, Abrahamov A, Hadas-Halpern I, et al. Adult-type Gaucher disease in children: genetics, clinical features and enzyme replacement therapy. Quarterly Journal of Medicine 1993; 86: $565-73$.

3. Martin B M, Sidransky E, Ginns E L. Gaucher's disease, advances and challenges. In: Barness LA, ed. Advances in Paediatrics. St. Louis, Mosby - Year book; 1989; 36: 277-306.

4. Daniels L B, Glew R H. Beta-glucosidase assays in the diagnosis of Gaucher's disease. Clin Chem 1982; 28: 569-77.

5. Aerts J M F G, Donker- Koopman W E, Koot M, Barranger J A. Tager J M, Schram A W. Deficient activity of glucocerebrosidase in urine from patients with type 1 Gaucher disease. Clin Chem Acta 1986; 158:155-63.

6. NIH Technology Assessment Conference. Gaucher Disease. Current Issues in Diagnosis and Treatment. JAMA 1996; 275(7): 548-53. 
